Check for updates

Cite this: RSC Adv., 2017, 7, 31582

Received 19th May 2017

Accepted 14th June 2017

DOI: $10.1039 / \mathrm{c} 7 \mathrm{ra05653b}$

rsc.li/rsc-advances

\section{Hollow mesoporous silica supported PtIr bimetal catalysts for selective hydrogenation of phenol: significant promotion effect of iridium $\uparrow$}

\begin{abstract}
Yuying Zheng, ${ }^{a}$ Peishan $\mathrm{He},{ }^{a}$ Yanxiong Fang, ${ }^{a}$ Xu Yang (D) *b and Huagen Liang ${ }^{\star c}$
Selective hydrogenation of phenol is of great significant for the production of Nylon 6. Herein, highly efficient and stable Ir promoted Pt catalysts for the hydrogenation of phenol are prepared by deposition of Pt-Ir nanoparticles onto hollow mesoporous silica spheres (HMSs) through a facile wet-impregnation and $\mathrm{H}_{2}$ reduction method. The obtained PtIr/HMS catalyst with Ir/Pt molar ratio of 0.1 shows a highest hydrogenation rate of $4255 \mathrm{mmol} \mathrm{h}^{-1} \mathrm{~g}_{\mathrm{Pt}}{ }^{-1}$ with cyclohexanone selectivity of $85 \%$ at $50{ }^{\circ} \mathrm{C}$ and $0.5 \mathrm{MPa}$ of $p_{\mathrm{H}_{2}}$ which is 3 times and 8.6 times higher than that of the mono Pt/HMS catalyst and commercial Pt catalyst, respectively. The trace addition of Ir promoter essentially contributes to the enhanced hydrogenation activity by improving the metal dispersion of Pt nanoparticles and promoting the charge transfer between the Pt and Ir. This work provides an effective protocol in developing high performance catalysts for phenol hydrogenation under mild reaction conditions.
\end{abstract}

\section{Introduction}

Catalytic hydrogenation of phenol is of industrial and scientific significance because cyclohexanone is an important intermediate for the production of Nylon 6 and Nylon $66 .{ }^{1}$ Thus, developing high performance catalysts for the selective hydrogenation of phenol to produce cyclohexanone under mild reaction conditions is an attractive topic in the field of catalysis and materials. ${ }^{2-4}$

A lot of research work on the development of the catalyst has been reported in the last decade. ${ }^{5-10}$ Current prevailing catalysts used for hydrogenation include Ni and Pd supported catalysts; the former ones are often operated under rigorous reaction conditions $\left(T>200^{\circ} \mathrm{C}\right.$ or $\left.\left.p_{\mathrm{H}_{2}}>1 \mathrm{MPa}\right),\right)^{11,12}$ the latter are confronted with severe metal sintering and leaching that often lead to deactivation issues. ${ }^{2,5,6}$ Noticeably, the Pt based catalysts exhibit excellent activity and stability under mild reaction conditions..$^{9,13,14}$ However, one major obstacle for practical application of Pt based catalysts is their scarce reserves and high cost. Therefore, several strategies have been tried to increase the Pt utilization efficiency, such as

\footnotetext{
${ }^{a}$ School of Chemical Engineering and Light Industry, Guangdong University of Technology, Guangzhou 510006, China

${ }^{b}$ Guangzhou Institute of Energy Conversion, Chinese Academy of Sciences, Guangzhou 510640, China. E-mail: yangxu@ms.giec.ac.cn; Tel: +86-020-87057620

${ }^{c}$ Low Carbon Energy Institute, School of Chemical Engineering \& Technology, China University of Mining and Technology,Xuzhou, 221116, China. E-mail: lhg654@ gmail.com; Tel: +86-0516-83883501

$\dagger$ Electronic supplementary information (ESI) available: Catalyst characterizations, schemes for reaction pathway and mechanistic proposition of phenol hydrogenation. See DOI: 10.1039/c7ra05653b
}

core-shell composites, ${ }^{15,16} \mathrm{Pt}$ monolayer catalysts, ${ }^{17,18}$ alloying with other metals, ${ }^{19}$ adding promoter, ${ }^{20,21}$ etc.

Of these protocols, adding promoter is both economically and effectively method due to its simple procedure and convenient controlling. Moreover, literatures elsewhere have envisioned that trace promoter not only can remarkably enhance the activity, but also tune the selectivity for various chemical reactions. For example, Tomita and co-authors have reported that addition of iron oxide can effectively improve the activity of $\mathrm{Pt} / \mathrm{Al}_{2} \mathrm{O}_{3}$ towards $\mathrm{CO}$ oxidation..$^{22}$ Burch et al. have investigated a series of $\mathrm{Pt} / \mathrm{Al}_{2} \mathrm{O}_{3}$ catalysts promoted by metal oxides or noble metals $(\mathrm{Ag}, \mathrm{Au}, \mathrm{Pd}, \mathrm{Rh})$ for the NO reduction, claiming that the promoters have a significant effect on the activity of $\mathrm{Pt} / \mathrm{Al}_{2} \mathrm{O}_{3} \cdot{ }^{21}$ Luo and co-authors have found that the Ir promoted $\mathrm{Ru} / \mathrm{ZnO}$ showed high selectivity towards crotyl alcohol applied in crotonaldehyde hydrogenation. ${ }^{23}$ They ascribed the improved selectivity to the modified electronic properties of $\mathrm{Ru}$ induced by the Ir promoter. These reports demonstrate well that high performance catalyst can be achieved as the promoters are elegant selected.

In this work, we attempt to obtain a high-performance Ir promoted Pt bimetal catalysts for selective hydrogenation of phenol. To the best of our knowledge, the promotion effect of Ir on the Pt towards phenol hydrogenation has seldom been reported. Previously, we have used our lab-made hollow mesoporous silica (HMS) as support of Pd catalyst for phenol hydrogenation. ${ }^{24}$ With high surface area $\left(\sim 800 \mathrm{~m}^{2} \mathrm{~g}^{-1}\right)$ and narrowed mesopores, the HMS can effectively disperse the Pd components. Moreover, the HMS can exert its inactive siliceous properties as an ideal candidate to investigate the promoter effect with less interruption by metal-support interaction. Thus, 
we herein selected the HMS as support to prepare PtIr/HMS catalysts with various molar ratio of Ir/Pt through impregnation and reduction route. The effect of promoter on the Pt based catalysts was investigated comprehensively as to explore the PtIr synergy effect on the performance towards hydrogenation of phenol.

\section{Experimental}

\section{Sample preparation}

Hollow mesoporous silica (HMS) were prepared according to route reported in document elsewhere: ${ }^{24} 0.5 \mathrm{~g}$ dodecyl amine as mesoporous template was dissolved in $20 \mathrm{ml}$ ethanol under mild stirring; after the addition of $50 \mathrm{ml}$ deionized water, $5 \mathrm{~g}$ TEOS was added drop-wise to obtain a white mixture; after 5 hours of stirring, white precipitates were obtained and then filtered, washed, dried, and calcinated at $600{ }^{\circ} \mathrm{C}$ for $2 \mathrm{~h}$ to remove the residual template.

Pt-Ir bimetallic catalysts with various molar ratio of $\mathrm{Ir} / \mathrm{Pt}$ (from 0 to 0.2 ) were prepared according to a wet-impregnation and $\mathrm{H}_{2}$ reduction route. Firstly, $1.0 \mathrm{~g}$ HMS supports were impregnated with $20 \mathrm{ml}$ ethanol solution of chloroplatinic acid $(0.03 \mathrm{~g})$ and chloroiridic acid $(0-0.008 \mathrm{~g})$ with given molar ratio, and kept stirring at room temperature. The solvent was then evaporated in a water bath at $50{ }^{\circ} \mathrm{C}$. The PtIr/HMS catalysts were finally prepared by reducing the sample under hydrogen flow at $300{ }^{\circ} \mathrm{C}$ for $4 \mathrm{~h}$ in a tubular furnace with programmed temperature control, at a rate of $2{ }^{\circ} \mathrm{C} \mathrm{min}^{-1}$. The Pt loading was fixed at $1.5 \%$ for all catalysts, and the basic specifications of catalysts are listed in Table 1. A commercial Pt/C catalyst was purchased from Aladdin agent Company for reference sample.

\section{Catalyst characterization}

X-ray diffraction (XRD) patterns were obtained with a X-ray diffract meter (Rigaku, Japan). The $\mathrm{N}_{2}$ adsorption-desorption isotherms were measured with a Tristar 3010 isothermal nitrogen sorption analyser (Micromeritics, USA) using a continuous adsorption procedure. High-resolution transmission electron microscopy (HRTEM) was carried out with a JEOL JEM2010 microscope (JEOL,

Table 1 Specifications of various catalysts

\begin{tabular}{|c|c|c|c|c|c|}
\hline \multirow[b]{2}{*}{ Catalyst } & \multirow{2}{*}{$\begin{array}{l}S_{\mathrm{BET}}{ }^{a} \\
\left(\mathrm{~m}^{2} \mathrm{~g}^{-1}\right)\end{array}$} & \multirow{2}{*}{$\begin{array}{l}D_{\text {Pore }}{ }^{a} \\
(\mathrm{~nm})\end{array}$} & \multicolumn{2}{|c|}{ Metal loading $^{b}$} & \multirow{2}{*}{$\begin{array}{l}D_{\mathrm{Pt}}{ }^{c} \\
(\mathrm{~nm}\end{array}$} \\
\hline & & & Pt wt $\%$ & Ir wt $\%$ & \\
\hline HMS & 837 & 3.7 & - & - & - \\
\hline $\mathrm{Pt} / \mathrm{C}$ & 56 & - & 5 & - & 4.2 \\
\hline $\mathrm{Pt} / \mathrm{HMS}$ & 821 & 3.3 & 1.50 & - & 3.8 \\
\hline PtIr0.05/HMS & 806 & 3.5 & 1.52 & 0.07 & 3.4 \\
\hline PtIr0.1/HMS & 812 & 3.5 & 1.48 & 0.16 & 3.2 \\
\hline PtIr0.2/HMS & 809 & 3.4 & 1.50 & 0.31 & 3.0 \\
\hline
\end{tabular}

${ }^{a}$ Surface area $\left(S_{\mathrm{BET}}\right)$ and pore size $\left(D_{\mathrm{Pore}}\right)$ were derived from the isothermal nitrogen ads-desorption curves. ${ }^{b}$ Metal loading was determined by ICP measurement. ${ }^{c}$ Average particle size of Pt crystallite $\left(D_{\mathrm{Pt}}\right)$ was calculated from the XRD plot according to the Scherrer equation.
Japan). X-ray photoelectron spectroscopy (XPS) with an AXIS Ultra DLD (Kratos, Britain) was used to examine the catalysts' electronic properties. The binding energies were calibrated using a $\mathrm{C} 1 \mathrm{~s}$ binding energy of $284.5 \mathrm{eV}$. $\mathrm{H}_{2}$-TPR was performed on an AutoSorb-iQ-c automated system (Quantachrom, USA): a sample of $50 \mathrm{mg}$ was heated at a rate of $10^{\circ} \mathrm{C} \mathrm{min}^{-1}$ from room temperature

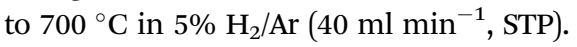

\section{Catalyst evaluation}

The hydrogenation of phenol was used for catalyst evaluation model reaction. The reaction mixture composed of $50 \mathrm{mg}$ catalyst, $0.5-1.0 \mathrm{~g}$ phenol, and $10 \mathrm{ml}$ acetate as solvent, was introduced into a $50 \mathrm{ml}$ autoclave under stirring at $1200 \mathrm{rpm}$, a value chosen to eliminate the mass transfer limitation. Air in the autoclave was purged by hydrogen for $20 \mathrm{~min}$, and then the reaction proceeded at the required temperature $\left(30-100^{\circ} \mathrm{C}\right)$ and $0.5 \mathrm{MPa}$ of $99.99 \%$ pure hydrogen. The products were analysed using a gas chromatograph GC2010 (Shimadzua, Japan) equipped with a FID detector.

\section{Results and discussion}

\section{Structure characterization of catalyst}

Fig. 1a shows the XRD patterns of the calcined HMS materials. A strong broad peak centred at $2.07^{\circ}$ of $2 \theta$ with a weak scattering
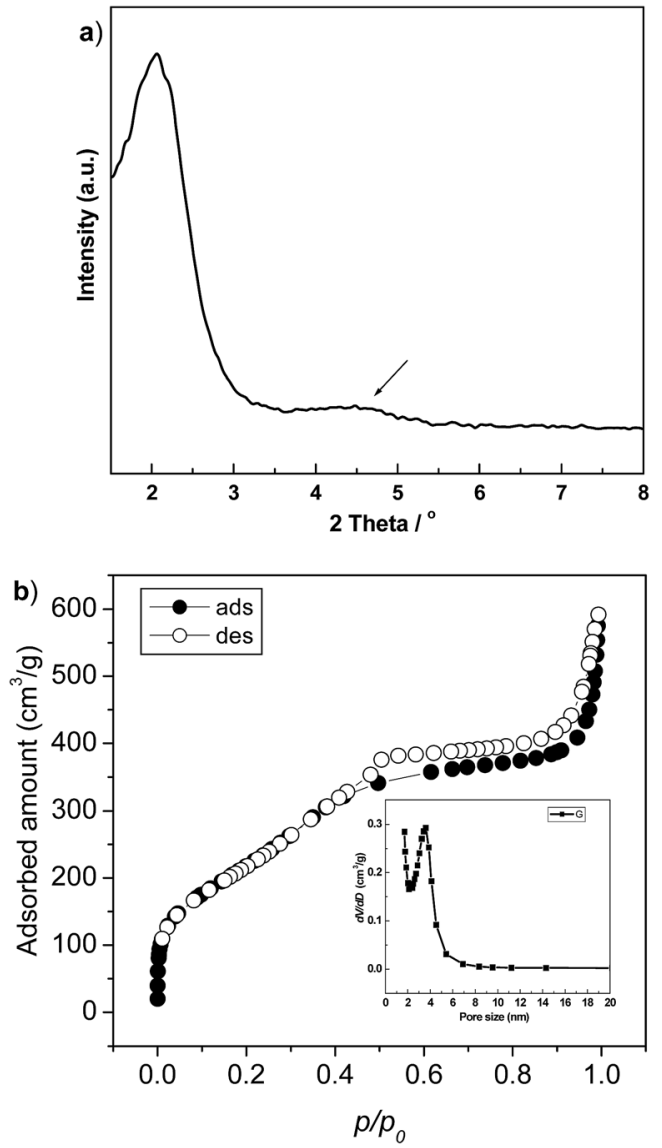

Fig. 1 Small angle XRD patterns (a) and isothermal $\mathrm{N}_{2}$ adsorptiondesorption plot (b) of the calcined HMS materials. 
domain (indicated by arrow) around $4-5^{\circ}$ of $2 \theta$ reveals the wormhole-like mesoporous structure of the sample. ${ }^{25}$ The corresponding isothermal $\mathrm{N}_{2}$ adsorption-desorption plot, shown in Fig. 1b, displays an obvious sorption step at $p / p_{\mathrm{o}}$ of 0.5 , assigning to the capillary condensation in the mesopores. ${ }^{26}$ The inset pore size distribution has a well-defined peak centred at $3.7 \mathrm{~nm}$. After loading of Pt nano-particles, all of the HMS supported catalysts reserved high surface area and narrowed mesopores size (seeing Table 1), indicating the good thermal stability of HMS.

Fig. 2 shows the wide-angle XRD patterns to characterize the metal crystallites of the catalysts. A broaden peak centred at $24^{\circ}$ of $2 \theta$ is observed for all samples, which is ascribed to the amorphous silica. The Pt/HMS exhibits three clear diffraction peaks located at $39.4,46.1$ and $66.9^{\circ}$ of $2 \theta$, indexing to the (111), (200), and (220) planes of the face-cantered cubic Pt crystallite. ${ }^{27}$ With the addition of Ir promoter, such three peaks become broadened and diminished, suggesting that the Ir promoter can weaken the crystalline degree of $\mathrm{Pt}$, or improve the metal dispersion. From the enlarged regional XRD between 30 and $50^{\circ}$, the half width of (111) peaks increase upon the Ir addition elevated. Table 1 presents the crystallite size calculated by the Scherrer equation. The particle size decreases from 3.8 to
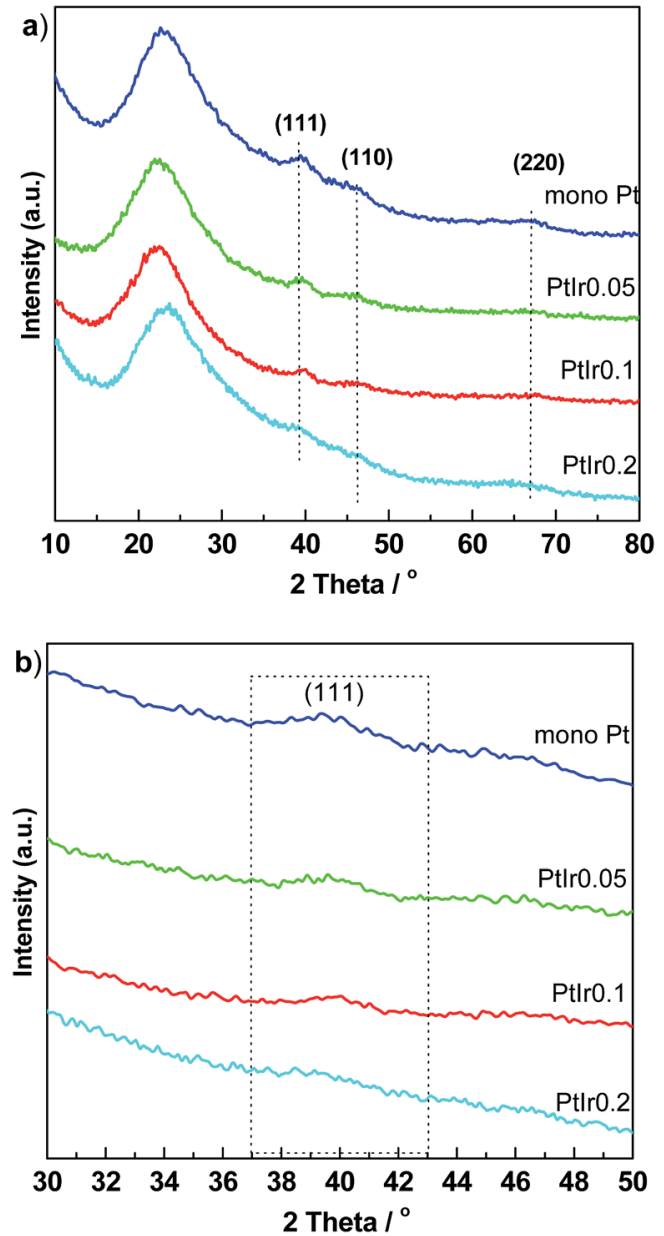

Fig. 2 Wide angle XRD pattern (a) and enlarged region between 30 and $50^{\circ}$ of $2 \theta$ (b) for PtIr/HMS catalysts with various Ir/Pt molar ratio.
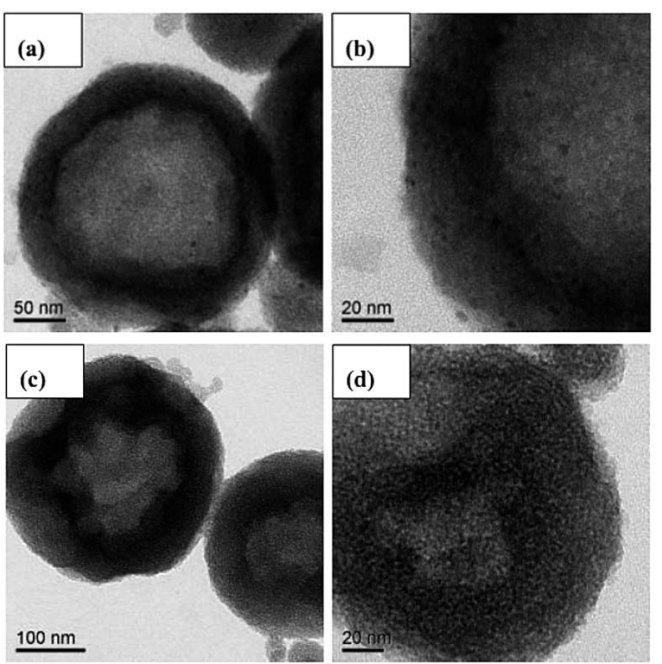

Fig. 3 TEM images of ( $a$ and $b$ ) Pt/HMS catalysts, (c and d) PtIr0.1/HMS catalysts.

$3.0 \mathrm{~nm}$ as the molar ratio of $\mathrm{Ir} / \mathrm{Pt}$ increase from 0 to 0.2 . It is clear that the addition of Ir promoter plays a crucial role for enhancing the dispersion and decreasing the particle size of $\mathrm{Pt}$ components.

Fig. 3 presents the TEM images of the mono-Pt/HMS and PtIr0.1/HMS catalysts for comparison. It verifies the microstructure of hollow cavity and mesoporous shell for the HMS support. In addition, the highly dispersion of active components on the HMS is seen clearly as well. The mono-Pt/HMS shows some poly-dispersed Pt nano-particles on the mesoporous shell (Fig. 3b), while the PtIr0.1/HMS presents homogeneously dispersed Pt nano-particles (Fig. 3d), further confirming the promotion effect of Ir on the metal dispersion.

To determine the crystallite size and lattice fringe of Pt nanoparticles precisely, the high-resolution TEM was conducted for these samples. As shown in Fig. 4, the PtIr0.1/HMS has a smaller particle size $(\sim 2 \mathrm{~nm})$ than that of the Pt/HMS $(\sim 4 \mathrm{~nm})$. Moreover, in the corresponding diffraction patterns, the PtIr0.1/ HMS exhibits less of diffraction light spots than the Pt/HMS does, implying its less crystalline degree or smaller particle

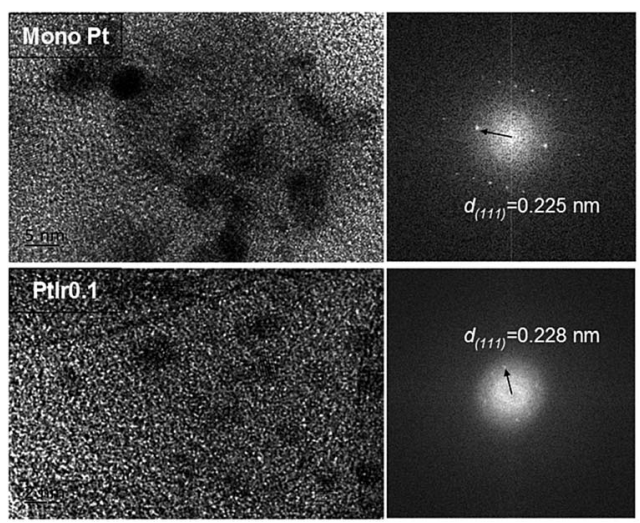

Fig. 4 HRTEM images of Pt/HMS and PtIr0.1/HMS catalysts. 
size, consistent with the XRD analysis. The (111) inter-planar distances derived from the diffraction pattern, indicate 0.218 and $0.228 \mathrm{~nm}$ for PtIr0.1/HMS and Pt/HMS, respectively, further revealing the contraction of Pt unit cell upon the addition of Ir. This can be associated with the formation of PtIr alloy. ${ }^{28,29}$ It demonstrates well that the addition of Ir promoter can result in the formation of PtIr alloy, and improve the metal dispersion.

$\mathrm{H}_{2}$-TPR profiles of the as-prepared catalysts after impregnation are presented in Fig. 5. The Pt/HMS exhibits a strong sharp peak located at approximately $117{ }^{\circ} \mathrm{C}$, attributable to the easy reducible $\mathrm{Pt}^{2+}$ ions. The PtIr0.1/HMS and PtIr0.2/HMS show a relative high temperature reduction peak centred at 177 and $191{ }^{\circ} \mathrm{C}$, respectively, which implies the hard reducible bimetal species on the catalysts. This can be ascribed to the strengthened interactions between the Pt precursors and silica, ${ }^{9}$ or to the formation of PtIr alloy. It demonstrates that the addition of Ir can intensify the metal support interaction, which would modulate the electronic properties of Pt phase.

Fig. 6 shows X-ray photoelectron spectroscopy (XPS) of samples to assess the surface information of metal states and compositions. The Pt $4 \mathrm{f}$ spectra can be fitted by two doublets attributed to the higher binding energy of $\mathrm{Pt}^{2+}(73.2-73.8 \mathrm{eV})$ and lower energy value of metallic $\mathrm{Pt}^{0}(71.9-72.2 \mathrm{eV}) .^{30}$ Compared with the Pt/HMS catalysts, a shift of $\sim 0.3 \mathrm{eV}$ towards high energy occurred for the bimetal PtIr0.1/HMS catalysts, indicating the electronic properties of $\mathrm{Pt}$ can be modulated by the Ir promoter. In addition, the XPS derived $\mathrm{Pt}^{0} / \mathrm{Pt}^{2+}$ atomic ratio indicates that the PtIr0.1/HMS held more of metallic Pt phase than the Pt/HMS has, suggesting the Ir promoter can resist the re-oxidation of metallic Pt species. It further verifies the modulation of electronic properties of Pt caused by the Ir promoter. The Ir $4 \mathrm{f}$ spectrum (Fig. 6c) indicates the $4 \mathrm{f}_{7 / 2}$ and $4 \mathrm{f}_{5 / 2}$ peaks at binding energy of 61.0 and $64.1 \mathrm{eV}$, respectively, assigning to the metallic state of Ir phase. ${ }^{31}$ The well-defined peak centred at $103.8 \mathrm{eV}$ is observable for both samples, corresponding to the $2 \mathrm{p}$ binding energy of silica.

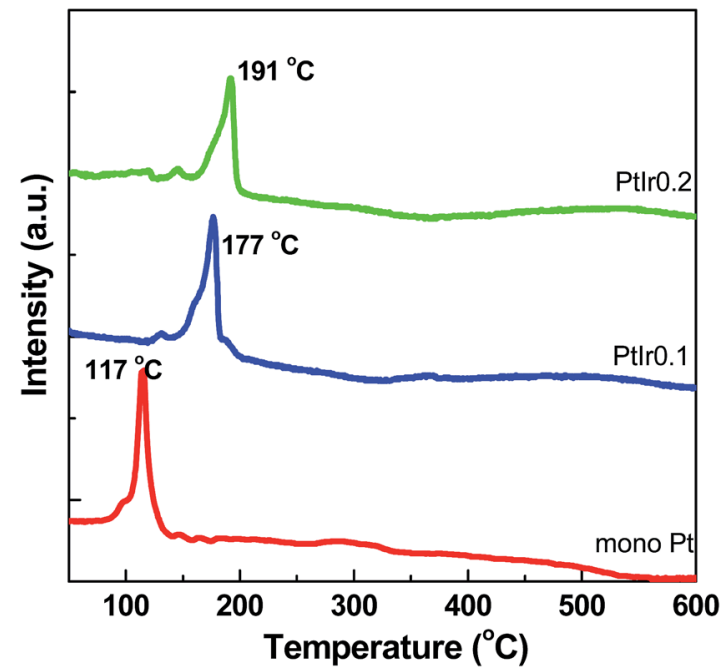

Fig. $5 \mathrm{H}_{2}$-TPR curves of PtIr/HMS catalysts with various Ir/Pt molar ratios.
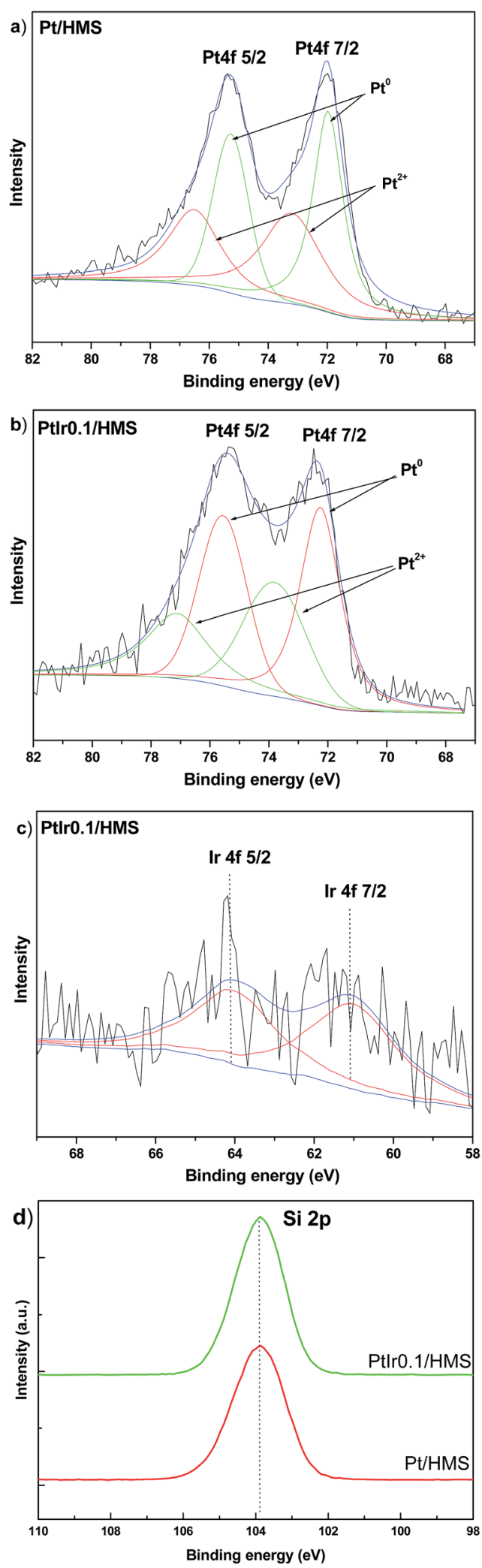

Fig. 6 XPS spectra of various catalysts: ( $a$ and b) Pt 4f, (c) Ir $4 f$ and (d) Si $2 \mathrm{p}$ in $\mathrm{Pt} / \mathrm{HMS}$ and PtIr0.1/HMS. 


\section{Catalytic performance of catalysts: hydrogenation of phenol}

Fig. 7a shows the catalytic performance towards hydrogenation of phenol over various catalysts. Generally, partial phenol hydrogenation yields cyclohexanone, and deep hydrogenation leads to the product of cyclohexanol, as shown the reaction pathway of Scheme S1 of (ESI $\dagger$ ). As the reaction proceeds at the similar conversion, all of $\mathrm{Pt}$ based catalysts show similar selectivity (80-85\%) towards cyclohexanone regardless of $\mathrm{Ir} / \mathrm{Pt}$ ratio, thus we focused our discussion on phenol conversion. The HMS is inactive under our conditions (not shown here). For the $\mathrm{Pt} / \mathrm{HMS}$, it converts $21 \%$ phenol, comparable with the commercial $\mathrm{Pt} / \mathrm{C}$ that with Pt loading of $5 \mathrm{wt} \%$, indicating the much higher Pt utilization efficiency than the commercial Pt/C. This suggests that the high surface area of HMS can facilitate the dispersion of Pt components, and improve the metal utilization efficiency. As the Ir promoter is introduced, the phenol conversion rises up to $38 \%$ over the PtIr0.05/HMS, and elevates to the highest value of $60 \%$ for the PtIr0.1/HMS. A high mass activity of $4255 \mathrm{mmol} \mathrm{h}^{-1} \mathrm{~g}_{\mathrm{Pt}}{ }^{-1}$ is achieved, which is 3 times and 8.6 times higher than the mono Pt/HMS catalyst and commercial Pt catalyst do, respectively.

Further increases the Ir addition, the conversion of PtIr0.2/ HMS shows a slight decline at 55\%. These results demonstrate that the Ir promoter could remarkably enhance the phenol hydrogenation activity; the optimum molar ratio of $\mathrm{Ir} / \mathrm{Pt}$
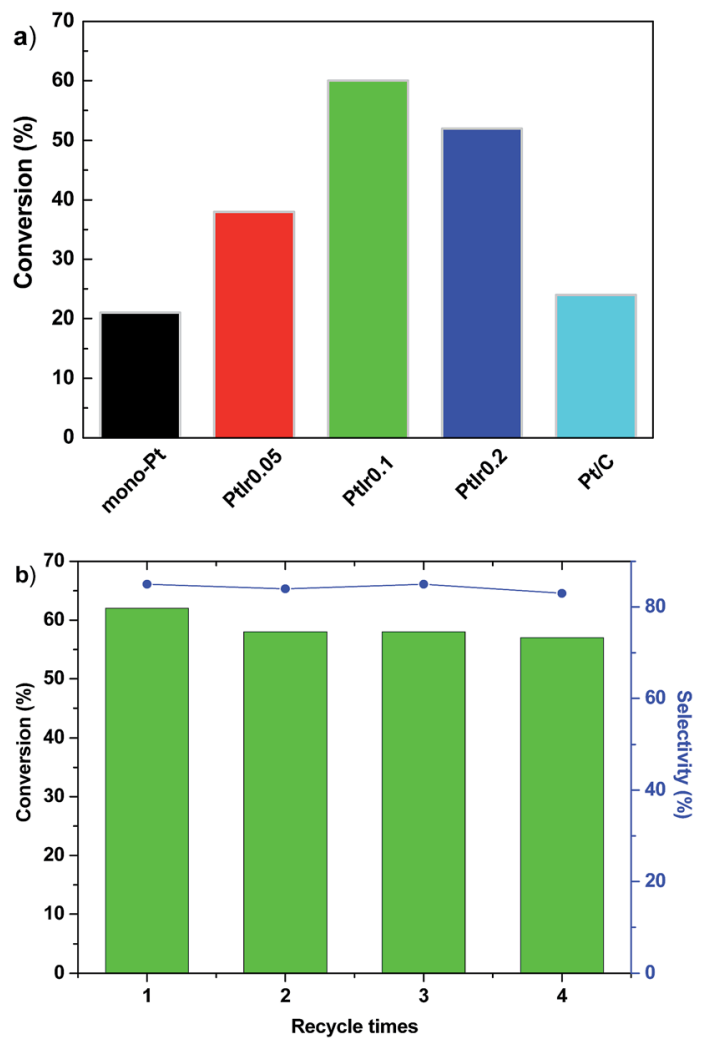

Fig. 7 (a) Phenol hydrogenation over various catalysts, (b) Recycle test over PtIr0.1/HMS. The reaction mixture composed of $50 \mathrm{mg}$ catalyst, $0.5 \mathrm{~g}$ phenol, and $10 \mathrm{ml}$ acetate as solvent, and proceeded at $50^{\circ} \mathrm{C}$ and $0.5 \mathrm{MPa}$ of $p_{\mathrm{H}_{2}}$ for $1 \mathrm{~h}$. is 0.1 . The recycle test was conducted for the PtIr0.1/HMS, as shown in Fig. 7b. After fourth run, it exhibits slight decline of conversion $(<2 \%)$, accompanied with constant selectivity of $84 \%$ towards cyclohexanone. The TEM images of spend catalyst (seeing Fig. S1 in ESI $\dagger$ ) after hydrogenation suggested negligible metal sintering, demonstrating the good stability of for the PtIr0.1/HMS catalyst.

Several limitations of the current catalytic system, such as harsh reaction conditions, deactivation and etc., have driven scientists to develop high-performance catalysts applied in mild reaction. ${ }^{7,25,32}$ Compared with the methods in documents elsewhere,,$^{\mathbf{5 , 6 1 0 - 1 4}}$ the high activity and good stability of the PtIr/HMS make it one of promising catalysts applied for phenol hydrogenation in mild reactions.

The influence of reaction temperature on the PtIr0.1/HMS was investigated, as shown in Fig. 8a. As the temperature is elevated from $30{ }^{\circ} \mathrm{C}$ to $100{ }^{\circ} \mathrm{C}$, the phenol conversion soars from $15 \%$ to $100 \%$. However, the selectivity of cyclohexanone decreases upon the increase of temperature, implying high reaction temperature facilitates deep hydrogenation of cyclohexanone to cyclohexanol. It reveals that the PtIr0.1/HMS is suitable for production of cyclohexanone through phenol hydrogenation under mild reaction. Based on the activity upon the reaction temperature, we plotted the Arrhenius curves for the Pt/HMS and PtIr0.1/HMS, as depicted in Fig. 8b. The apparent activation energy was 39.5 and $31.4 \mathrm{~kJ} \mathrm{~mol}^{-1}$ for Pt/
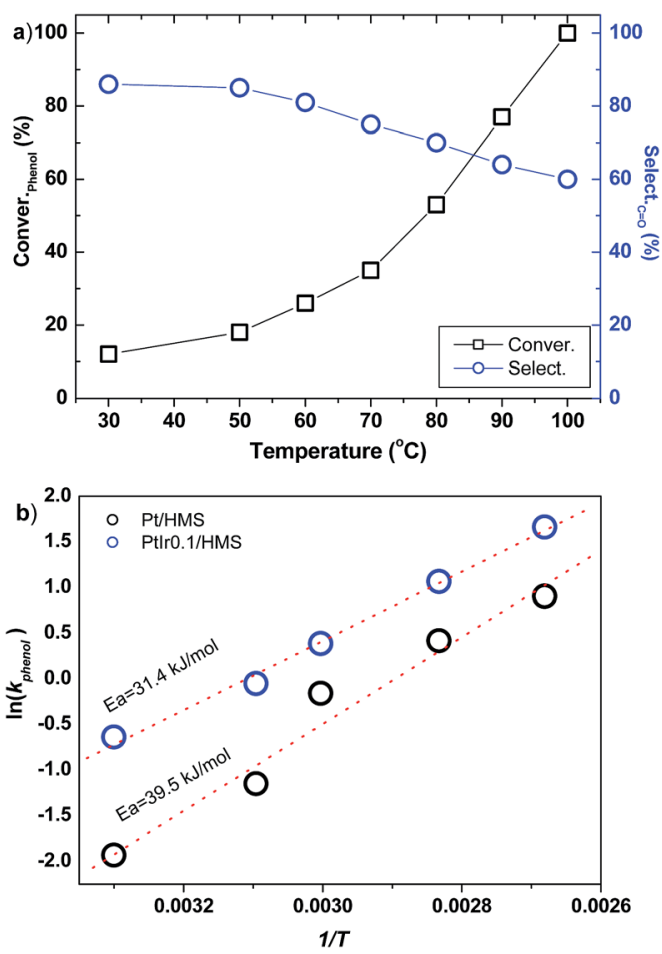

Fig. 8 (a) Phenol hydrogenation over PtIr0.1/HMS upon temperature evolution; (b) corresponding Arrhenius plots of various catalysts. The reaction mixture composed of $50 \mathrm{mg}$ catalyst, $1 \mathrm{~g}$ phenol and $10 \mathrm{ml}$ acetate as solvent, and proceeded with $0.5 \mathrm{MPa}$ of $p_{\mathrm{H}_{2}}$ for $0.5 \mathrm{~h}$; the selectivity towards cyclohexanone was determined at the conversion of $10 \%$ for each run. 
HMS and PtIr0.1/HMS, respectively, further verifying the promotion effect of Ir on the Pt.

\section{Promotion effect of Ir on the Pt based catalyst}

Considering that the Pt loadings of catalysts are fixed at $1.5 \%$, the activity enhancement can be ascribed to the promoter effect of Ir. The promotion effect on the activity can be ascribed to the improved metal dispersion and modulated electronic state. As justified by the XRD and TEM results, the PtIr alloy effectively hinders the particle growth. Higher metal dispersion means more of active sites, resulting in accelerated hydrogenation reaction. With respect to the electronic modulation, as shown in TPR and XPS analysis, it verifies the intensified metal-support interaction and charge transfer induced by the Ir promoter, and both can influence the catalytic behaviour of reactants and intermediates (e.g. dissociative, ads-desorption, etc.) during hydrogenation.

\section{Conclusions}

A high-performance Ir promoted Pt catalyst for hydrogenation of phenol is prepared using the hollow mesoporous silica sphere (HMS) as support through a facile wet-impregnation and $\mathrm{H}_{2}$ reduction method. The obtained PtIr0.1/HMS catalyst (with Ir/Pt molar ratio of 0.1) shows highest hydrogenation rate of $4255 \mathrm{mmol} \mathrm{h}^{-1} \mathrm{~g}_{\mathrm{Pt}}{ }^{-1}$ (with cyclohexanone selectivity of $85 \%$ ) at $50{ }^{\circ} \mathrm{C}$ and 0.5 MPa of $p_{\mathrm{H}_{2}}$, which is 3 times and 8.6 times higher than that the mono Pt/HMS catalyst and commercial Pt/C catalyst, respectively. The addition of Ir promoter essentially contributes to the enhanced hydrogenation activity by improving the metal dispersion of Pt nanoparticles and promoting the charge transfer between the Pt and Ir. This work provides an effective protocol in developing a high performance catalyst for phenol hydrogenation under mild reaction conditions.

\section{Acknowledgements}

This work was supported by the National Scientific Foundation of China (project No. 21303210), and Open Project Program of the State Key Lab of CAD\&CG (Grant No. A1701) Zhejiang University.

\section{Notes and references}

1 J. B. J. H. van Duuren, B. Brehmer, A. E. Mars, G. Eggink, V. A. P. M. dos Santos and J. P. M. Sanders, Biotechnol. Bioeng., 2011, 108, 1298.

2 N. Mahata and V. Vishwanathan, J. Catal., 2000, 196, 262. 3 Z. Li, J. Liu, C. Xia and F. Li, ACS Catal., 2013, 3, 2440.

4 P. M. Mortensen, J.-D. Grunwaldt, P. A. Jensen and A. D. Jensen, ACS Catal., 2013, 3, 1774.

5 S. Narayanan and K. Krishna, Appl. Catal., A, 1996, 147, L253.
6 E. Díaz, A. F. Mohedano, L. Calvo, M. A. Gilarranz, J. A. Casas and J. J. Rodríguez, Chem. Eng. J., 2007, 131, 65.

7 H. Liu, T. Jiang, B. Han, S. Liang and Y. Zhou, Science, 2009, 326, 1250.

8 Y. Wang, J. Yao, H. Li, D. Su and M. Antonietti, J. Am. Chem. Soc., 2011, 133, 2362.

9 X. Yang, X. Yu, L. Long, T. Wang, L. Ma, L. Wu, Y. Bai, X. Li and S. Liao, Chem. Commun., 2014, 50, 2794.

10 J. He, C. Zhao and J. A. Lercher, J. Am. Chem. Soc., 2012, 134, 20768.

11 E.-J. Shin and M. A. Keane, Ind. Eng. Chem. Res., 2000, 39, 883.

12 C. Zhao, S. Kasakov, J. He and J. A. Lercher, J. Catal., 2012, 296, 12.

13 K. Amouzegar and O. Savadogo, Electrochim. Acta, 1998, 43, 503.

14 Y. Song, O. Y. Gutiérrez, J. Herranz and J. A. Lercher, Appl. Catal., B, 2016, 182, 236.

15 S. Alayoglu, A. U. Nilekar, M. Mavrikakis and B. Eichhorn, Nat. Mater., 2008, 7, 333.

16 S. H. Joo, J. Y. Park, C.-K. Tsung, Y. Yamada, P. Yang and G. A. Somorjai, Nat. Mater., 2009, 8, 126.

17 M. Shao, K. Shoemaker, A. Peles, K. Kaneko and L. Protsailo, J. Am. Chem. Soc., 2010, 132, 9253.

18 A. U. Nilekar, K. Sasaki, C. A. Farberow, R. R. Adzic and M. Mavrikakis, J. Am. Chem. Soc., 2011, 133, 18574.

19 B. Habibi, M. H. Pournaghi-Azar, H. AbdolmohammadZadeh and H. Razmi, Int. J. Hydrogen Energy, 2009, 34, 2880.

20 T. Frelink, W. Visscher and J. A. R. van Veen, Surf. Sci., 1995, $335,353$.

21 R. Burch and T. C. Watling, Appl. Catal., B, 1997, 11, 207.

22 A. Tomita, K.-i. Shimizu and Y. Tai, Catal. Lett., 2014, 144, 1689.

23 B. Li, X. Hong, J.-J. Lin, G.-S. Hu, Q. Yu, Y.-J. Wang, M.-F. Luo and J.-Q. Lu, Appl. Surf. Sci., 2013, 280, 179.

24 X. Yang, S. Liao, J. Zeng and Z. Liang, Appl. Surf. Sci., 2011, 257, 4472.

25 X. Yang, L. Du, S. Liao, Y. Li and H. Song, Catal. Commun., 2012, 17, 29.

26 P. T. Tanev and T. J. Pinnavaia, Chem. Mater., 1996, 8, 2068.

27 T. Zhu, C. Du, C. Liu, G. Yin and P. Shi, Appl. Surf. Sci., 2011, 257, 2371.

28 X. Yang, D. Chen, S. Liao, H. Song, Y. Li, Z. Fu and Y. Su, J. Catal., 2012, 291, 36.

29 X. Yang, C. Huang, Z. Fu, H. Song, S. Liao, Y. Su, L. Du and X. Li, Appl. Catal., B, 2013, 140, 419.

30 Y. Li, G.-H. Lai and R.-X. Zhou, Appl. Surf. Sci., 2007, 253, 4978.

31 G. S. Fonseca, G. Machado, S. R. Teixeira, G. H. Fecher, J. Morais, M. C. M. Alves and J. Dupont, J. Colloid Interface Sci., 2006, 301, 193.

32 A. Li, K. Shen, J. Chen, Z. Li and Y. Li, Chem. Eng. Sci., 2017, 166, 66. 